\title{
ANALYSING THE CONVERTER REQUIREMENTS FOR A DUAL-FED INDUCTION MACHINE BASED FLYWHEEL ENERGY STORAGE SYSTEM
}

\author{
Christian Klumpner
}

\author{
Department of Electrical and Electronic Engineering, University of Nottingham, UK \\ klumpner@ieee.org
}

Keywords: Dual-fed induction machine, Efficiency, Energy storage, Flywheel, Power converter, Power losses.

\begin{abstract}
The Dual-fed Induction Machine was used very successfully in wind generators as it allowed full control of the power captured from the wind within a wide relevant rotational speed range around the synchronous speed needing only a low power rated rotor side converter to control the power extraction. Flywheel energy storage is also characterised by the need to operate at a relatively high speed range whereby large amounts of kinetic energy can be stored with a relatively small inertia, whilst operation at low speed is not needed. This paper aims at investigating how the rotor side converter technical specification is influenced depending on the rated power of the flywheel energy storage system and compare the typical converter power losses of a DFIM based flywheel storage with a squirrel cage induction machine that requires the bidirectional converter to process all storage power.
\end{abstract}

\section{Introduction}

A dual-fed induction machine (DFIM) relies on a wound rotor induction machine that has the stator winding connected directly to the constant voltage/constant frequency power grid whilst the rotor winding is connected via a bidirectional power converter to the same grid. A step up transformer may be used for the rotor side converter in case the stator connects to a medium voltage grid whilst the rotor side converter is low voltage rated $(<1 \mathrm{kV})$ rated to minimise cost, as shown in Fig. 1 and this is the typical arrangement used in most DFIG based wind turbines. In order to understand the reasons why the DFIG arrangement was so successful in wind generators we need to analyse the particularities of this application and how these impacts the ratings of the rotor side converter [1]-[2].

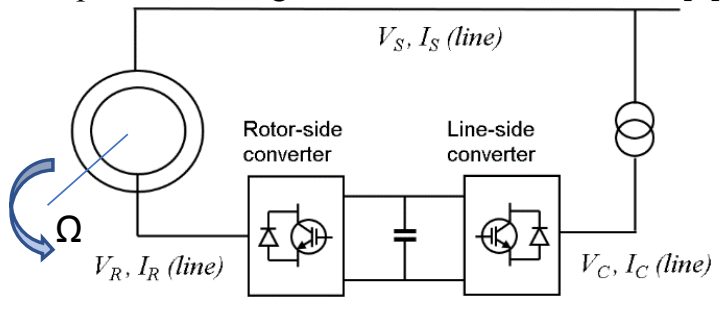

Fig. 1. Circuit diagram of a DFIM

The 4-quadrant of DFIM operation is shown in Fig. 2 where the horizontal axis is the slip (positive slip which is equivalent subsynchronous operation is shown on the left side whist supersynchronous operation is show on the right side) whilst on the vertical axis the electromagnetic torque is shown. Due to the fact that the direction of rotation for the stator magnetic flux remains the same, positive torque (upper range) will always represent operation in motoring mode whilst negative torque (bottom range) will always represent operation in generation mode.

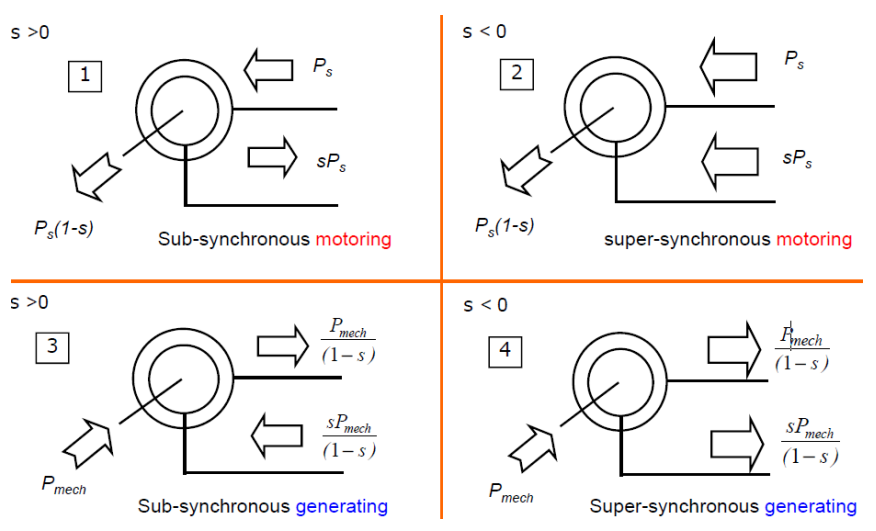

Fig. 2. 4-quadrant power vs slip characteristic of a DFIM [2]

In a DFIG based wind generator application, the electromagnetic torque has the same direction (negative) opposing the movement of the shaft. Also, there is a quadratic/cubic relationship between the expected mechanical torque/power produced by the blades at the generator shaft with the shaft speed which means that when the DFIG operates in subsynchronous mode (light wind speeds), a lower shaft torque would require smaller rotor side currents and relatively small amount of power injected in the rotor winding. When the wind generator operates in the upper speed range which is above the synchronous speed (quadrant 4), it is expected that the captured electrical power that approaches the rated power of the wind turbine will be evacuated from the DFIG via both stator and rotor windings which means that the wind generator rated power can be significantly larger than the power rating of the stator winding therefore the actual electrical machine is cheaper and lighter than an equivalent squirrel cage induction machine generator and also that the efficiency at rated power (top speed) is larger since the stator power which makes for most of the electrical power extracted is directly delivered to the power grid without having to pass through intermediary 
conversion stages, therefore not being subject to additional losses. During operation in subsynchronous mode, power needs to be injected in the rotor and extracted via the stator which means the rotor power is circulating via the DFIM's rotor and stator windings then back to the rotor via the step down transformer and the rotor side converter. For this reason, losses as percentage of wind generator power processed are significant, but since the speed is relatively small, electromagnetic torque and consequently the rotor currents are significantly smaller therefore in absolute terms, these losses are not problematic from a thermal stress point of view.

If the DFIM is used in flywheel energy storage applications [3]-[4], both directions of the electromagnetic torque needs to be available to provide unrestricted charge and discharge of the flywheel energy storage system (F-ESS). One clear disadvantage of F-ESS using a DFIM is that stator frequency which dictates the rotational speed of the magnetic field in the machine is constant and always linked to the frequency of the grid and therefore the highest synchronous speed is when the number of pair of poles is the lowest $(p=1)$ which means that the synchronous speed is fixed 3,000 or $3,600 \mathrm{rpm}$ for a $50 / 60 \mathrm{~Hz}$ grid which means rotational speeds may be limited to $4,000 \mathrm{rpm}(50 \mathrm{~Hz})$ or $4800 \mathrm{rpm}(60 \mathrm{~Hz})$ for a maximum slip of 0.33 which guarantees a reasonable small rating for the rotor side power converter. This will require significantly larger/heavier flywheels in case these are directly connected to DFIM's shaft or would require the use of a gearbox which may complicate the mechanical design. On the other hand, lower speed flywheels will be less subject to friction loss and therefore, encapsulation in a vacuum flask may not be needed.

In case a direct drive connection is needed to a high speed flywheel, other type of electrical machines need to be considered where the rotational speed of the magnetic field is fully adjustable by the frequency/power converter that is connected to their stator windings but the electrical decoupling between frequency of the winding/field in the machine and the power grid is obtained at the cost of having to process all electrical power via the power converter which means higher losses at rated power due to the additional stages inserted in the power flor and higher costs. However, there may be some potential other advantages which are not immediately obvious and this is why the evaluation of converter requirements for a DFIM based F-ESS needs to be conducted in comparison to one of the "full converter scale" option.

The following machines can be considered to be used din a FESS: the squirrel cage induction machine [5], the permanent magnet synchronous machine (here there are different types of construction dependent on the way the permanent magnets are integrated within the stator), synchronous reluctance machines where there are no magnets/excitation present on the rotor and the electromagnetic torque is produced by the anisotropy in the rotor reluctance [6]. Before discussing briefly these options, the way ESS are usually exploited needs to be clarified.

When using an ESS, the user wants to regard the ESS as a black box and be able to set a power demand within the +/limits set by the rated power of ESS which then needs to be delivered by the ESS (flywheel + associated electric drive) as long as the state of charge (N.B. this term is usually causing confusion since "charge" can be associated to "electrical charge" but also to describe with how much energy the ESS is "charged" which is used with any type of ESS not only electrochemical based; in this paper, the latter meaning will be used). Whilst in an electrochemical battery voltage remains relatively constant, the SOC range represents in fact the relative electrical charge than can be stored in the electrode material and this can be accessed with reasonable currents at any electrical power (when voltage remains relatively constant, the electrical battery current is proportional to required power). However, in a supercapacitor or flywheel based ESS, the energy is proportional with square the voltage/speed which means a quadratic dependency between the main state variable of supercapacitor/flywheel and the amount of energy stored. On the other hand, the power that can be delivered by the supercap/flywheel ESS is a product of supercap voltage and current or in case of a flywheel, between speed and torque. This means that in the low voltage/speed range, a significantly larger electrical current/mechanical torque, which may relate to the active current of an electrical machine depending on type and operating mode (i.e. constant torque or constant power) will be required. For this reason, it is customary to limit the minimum voltage/speed of a supercap/flywheel ESS to a level where the required current ratings and the associated losses remain reasonable. It can also be noted that if the minimum voltage/speed is $30 \%$ of maximum/rated level, the energy extraction reaches $91 \%\left(1^{2}\right.$ $0.3^{2}$ ) of the maximum energy that can be stored by the supercap/flywheel.

As mentioned above, it is possible to exploit the electrical machine in any of the two operating modes: constant power/flux which is available for speeds up to base speed (speed where at nominal frequency, the stator winding is supplied with rated voltage). Below the base speed, voltage and frequency need to be adjusted in same proportion (constant $\mathrm{V} / \mathrm{Hz}$ ) to avoid saturation of the magnetic circuit but this means that electrical power processed is proportional to speed/frequency. However, as mentioned earlier, an F-ESS user will expect unrestricted access to power and not having an available power dependable on the rotational speed (which is quadratic with SOC of the flywheel). For this reason, it is expected that most F-ESS to work in the constant power mode also referred as the field weakening mode where the magnetic flux is reduced to account for a limited voltage available from the associated power converter. This means that a flywheel will always have to operate above base speed. SCIM and RSM are in fact ideal for operation in a wide speed range of field weakening mode whilst PMSM, having the permanent magnets constantly delivering a magnetic flux, will require significant amounts of reactive (inductive behaviour) currents to demagnetise the machine at higher speeds in order to maintain the stator voltage constant. In this paper, a SCIM is used as a comparison benchmark to evaluate the converter requirements of the DFIM F-ESS which will include determining the voltage, current and peak power processing requirements of both stages of the bidirectional converter connecting the rotor winding of DFIM to the grid and the 
semiconductor power losses. In order to avoid the use of a grid side step up transformer, the stator to rotor turns ratio will be adjusted so that at maximum slip, the peak AC voltage seen on the rotor side circuit matches the grid side.

\section{Analysing the converter stresses for a DFIM based Flywheel Energy Storage}

In a constant power application, the mechanical torque is inverse proportional with the rotational speed:

$P_{\text {mech }}=T_{\operatorname{mech} @ \Omega \max } \cdot \Omega_{\max }=T_{\operatorname{mech} @ \Omega \min } \cdot \Omega_{\min }$

In a DFIM, the dependency between stator, rotor and mechanical powers are defined by as illustrated in Fig. 3a:

$\mathrm{P}_{\mathrm{S}}=\mathrm{P}_{\text {mech }} /(1+\mathrm{s}) \quad$ where $\mathrm{s}=\left(\Omega_{\text {sync }}-\Omega\right) / \Omega_{\text {sync }}$

$\mathrm{P}_{\mathrm{R}}=\mathrm{s} \cdot \mathrm{P}_{\mathrm{S}}=\mathrm{s} \cdot \mathrm{P}_{\text {mech }} /(1+\mathrm{s})$

Also the voltage induced in the rotor winding by the rotor winding "slipping" in the constant stator magnetic flux is given by (4), reaching zero at synchronism, as illustrated in Fig 3b:

$\mathrm{V}_{2}=\mathrm{V}_{20} / \mathrm{s}$

where $\mathrm{V}_{20}$ is the rotor open circuit voltage with rotor locked.

If the speed range of the DFIM based F-ESS is chosen in order to operate at maximum slip/rotor voltage at both minimum and maximum speed in order to fully utilise the converter voltage rating, the following can be defined:

Maximum speed:

Minimum speed:

And the speed range:

$$
\begin{aligned}
& \Omega_{\max }=\Omega_{\text {sync }} \cdot\left(1+\left|\mathrm{s}_{\max }\right|\right) \\
& \Omega_{\min }=\Omega_{\text {sync }} \cdot\left(1-\left|\mathrm{s}_{\max }\right|\right) \\
& \Omega_{\max }-\Omega_{\min }=2 \cdot\left|\mathrm{s}_{\max }\right| \cdot \Omega_{\text {syn }}
\end{aligned}
$$

If it is desired to eliminate the adapting transformer that connects the rotor winding to the grid via the bidirectional power converter, the voltage ratings of the stator $\mathrm{V}_{1 \mathrm{~N}}$ needs to be the same as the maximum rotor voltage which can be done by imposing $\mathrm{V}_{20}$ which is a design parameter for a DFIM:

$\mathrm{V}_{1 \mathrm{~N}}=\mathrm{V}_{2 @ \text { smax }}=\mathrm{V}_{20} / \mathrm{s}_{\max }$

which will result in the required $\mathrm{V}_{20}$ voltage rating for a given stator rated voltage $\mathrm{V}_{1 \mathrm{~N}}$ and maximum slip $\mathrm{s}_{\max }$. It should be noted that in the equation above, both voltages are line-to line. If the DFIM designer requires that the windings voltages to be specified, it should be taken into account that it is common to employ a delta winding connection in the stator and a star connection in the rotor winding therefore, the stator to rotor winding's turns ratio should be adjusted accordingly.

It is assumed that the rotor current is solely used to produce torque current (magnetisation is done via the stator winding only) therefore it can be assumed that the rotor current is proportional with torque. In addition, if the constant power restriction is added, the relation between rotor currents at minimum and maximum speed range can be derived:

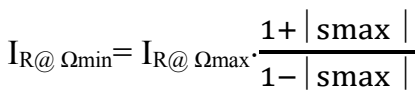

which means that if $s_{\max }=0.33$, the rotor current at minimum speed needs to be twice $(1.33 / 0.66=2 \mathrm{x})$ larger than at maximum speed for the same power processed by the F-ESS.
This situation is also illustrated in Fig. $3 \mathrm{c}$ and it can be seen that this is a linear dependency on slip.

It is also possible to plot the percentage of extracted energy from the flywheel inertia depending on the speed range, as function of maximum stored energy (as $\mathrm{s}=-0.33$ ) and this is shown in Fig. 3d.

$\Delta \mathrm{E} / \mathrm{E}_{\max }=100 \cdot\left[1-\left(\frac{1-s}{1+\operatorname{smax}}\right)^{2}\right] \%$
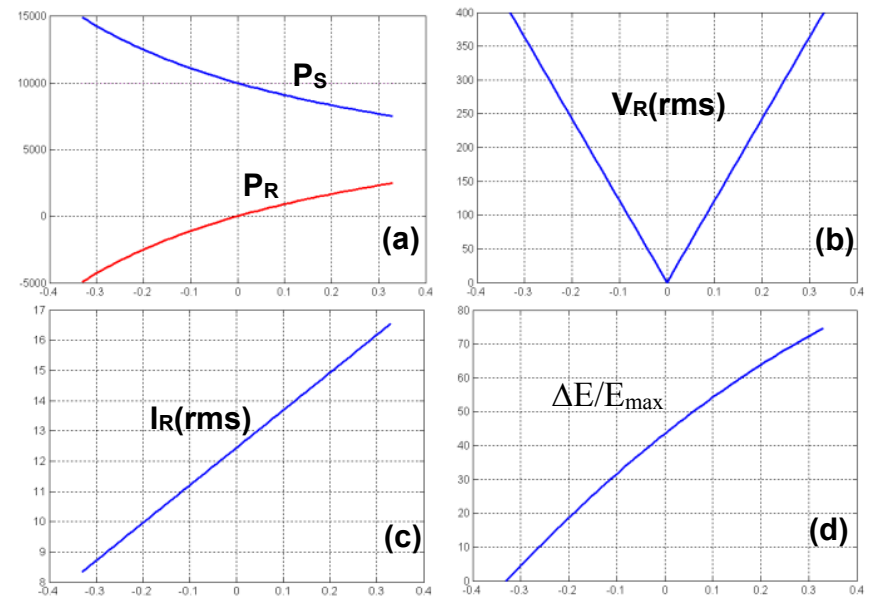

Fig. 3. Variation vs slip of key DFIM parameters for a $10 \mathrm{~kW}$ F-ESS: a) stator and rotor powers; b) rotor line voltage; c) rotor current; d) energy extraction as percentage of maximum. (N.B.maximum speed is on left side of the graph @s=-0.33)

It can be seen that whilst the maximum current raises linearly with the slip, the energy extraction tends to level which means that maximising the energy extraction beyond $70 \%$ of the maximum stored energy will be costly in terms of converter current rating and associated losses.

\section{Implementing the DFIM model for the Flywheel Energy Storage System}

In order to model the behaviour of the DFIM based F-ESS, it is necessary to implement a suitable simulation model. PSIM simulation software that is specialised in modelling power electronics, motor drives and the associated control and also estimate losses in the power semiconductors by using experimental data as provided in datasheets $[\mathrm{xx}]-[\mathrm{xx}]$ for conduction and switching losses of a particular power semiconductor chosen to be able to handle the voltage and current stresses experienced by the model.

A $10 \mathrm{~kW}$ DFIM with a 0.3 turns ratio has been used which at maximum slip gives same voltage amplitude as the power grid. Due to the need to simulate in detail the power converters in order to get a reasonable estimation of losses, a short chargedischarge cycle $(\mathrm{f}=0.5 \mathrm{~Hz})$ is considered. Also, in order to avoid interaction of the large overshoots caused by the large transients that appear during the power reversal with the current controller stability, the following simplifications were added to avoid any unwanted instabilities:

- The control structure shown in Fig. 4 has been employed that enables the active current reference component to be derived from the power reference signal and actual rotational speed. 
- The power converter has been replaced by linear amplifiers in the simulation of DFIM system

- A switch mode voltage source inverter running in open loop and being controlled by same reference voltages that drive the linear amplifiers and being loaded with controllable current sources mimicking the rotor currents was used to estimate the losses of the power semiconductor.

- A similar grid connected voltage source inverter model controlled by a typical dq control (not shown) decoupled from the rotor converter but being fed in the DC-link by a current source mimicking the calculated rotor power was used to estimate the semiconductor power losses of the grid side converter.

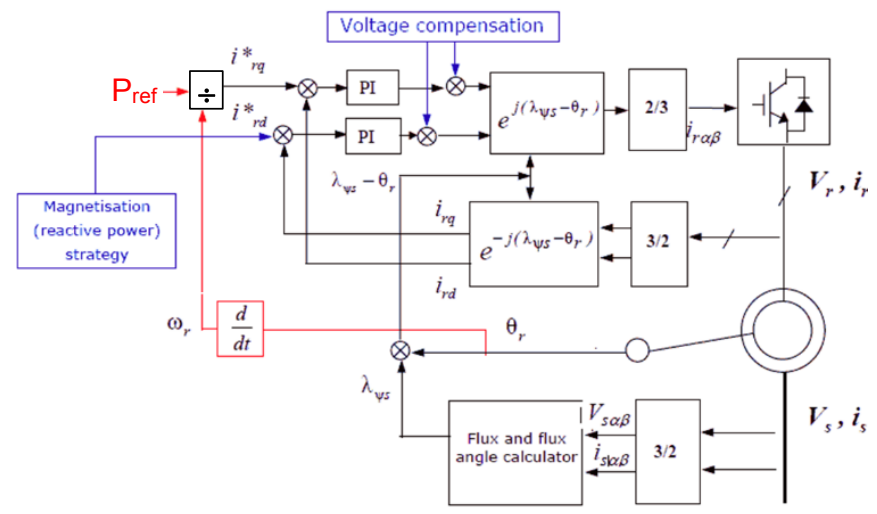

Fig. 4. Typical decupled control of DFIM's rotor side converter based on stator flux oriented synchronous frame based on rotor position of the [2]

\section{$4 \quad$ Simulation Results}

\subsection{Simulation results of the DFIM based F-ESS}

A simulation model representing a flywheel based ESS that uses a 2-pole DFIM $\left(\mathrm{n}_{\mathrm{s}}=3,000 \mathrm{rpm}\right)$ performing a $10 \mathrm{~kW}$ constant power charge/discharge cycling is developed in PSIM. Fig 5a shows the 2,000-4,000rpm speed range which is symmetrical around the synchronous speed $\left(\mathrm{s}_{\max }=0.33\right)$. Accordingly, the rotor phase voltage and the corresponding envelope (magnitude of phase voltage vector) which is proportional with the slip, is show in Fig 5b. In order to keep the mechanical power to the flywheel constant, electromagnetic torque that is controlled by the active rotor current vector, needs to be inverse proportional sith the shaft speed, as depicted in Fig 5c. Fig. 5d shows one of the rotor currents and the magnitude of the rotor current vector which mimics the shape of the torque rotor current (absolute value). The rotor phase voltage and current can be used to calculate the amount of power processed by the rotor side converter as shown in Fig.5e. Although the average power processed is $2 \mathrm{~kW}$ it reveals two significant peaks at maximum and minimum speed but due to the different torques requited at max and minimum speeds, the power peak at minimum speed $(6 \mathrm{~kW})$ is twice larger which shows that it is very costly to operate the F-ESS at lower speed. This situation is very similar to operation of a supercapacitor based ESS where the supercap voltage vs energy stored changes in the same way the speed in a F-ESS and the requirement to maximise energy extraction at low supercap voltages will require excessive currents (and losses) which the converter needs to be designed to handle.
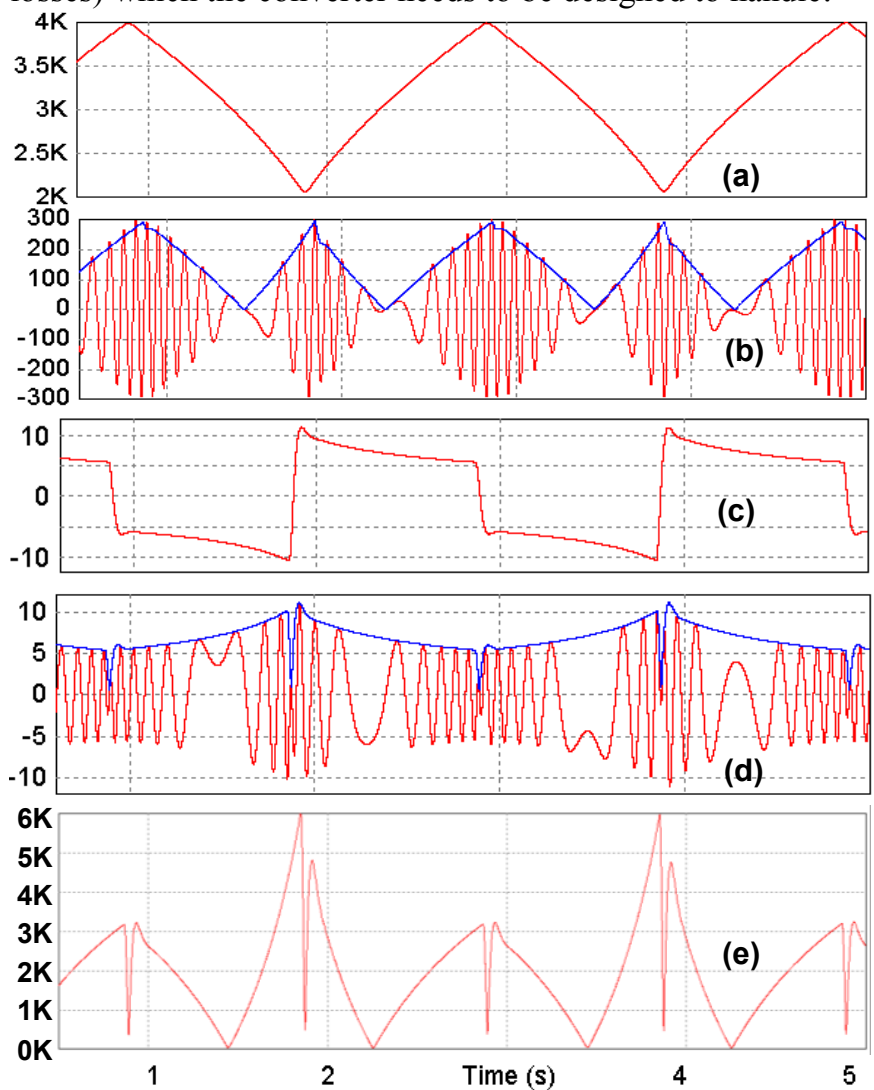

Fig. 5. Operation of a 2-pole DFIM in constant power chargedischarge mode $(10 \mathrm{~kW})$ : a) speed; b) rotor side phase voltage and vector magnitude; c) rotor current d-axis (torque) current; d) Rotor side phase current and its vector magnitude; e) instantaneous power processed by the rotor side converter.

One may observe that the processed power at $\mathrm{s}=+0.2(\mathrm{t}=2 \mathrm{~s}$ when $n=2,200 \mathrm{rpm})$ is the same as the processed power at maximum speed $\mathrm{s}=-0.33(\mathrm{t}=2.8 \mathrm{~s}$ when $4,000 \mathrm{rpm})$ however, the rotor current at lowest speed is significantly higher $(1 / 0.6=1.67$ times) and the rotor voltage is lower. The reason is that in constant power applications, the rotor current is proportional to the torque which is inverse proportional to the speed.

Fig. 6 shows the power flows of the rotor side converter which is then injected in the power grid. To achieve this, the grid side converter needs to process an active power replicating the active power handled by the rotor side converter. Since the grid voltage remains constant, the d-axis (active) current needs to be shaped similarly as the rotor active power and this is can be seen in Fig $6 \mathrm{~b}$ where one of the grid phase current and the magnitude of the grid current vector is shown (reactive current is controlled to be zero). The power processed by the DFIM stator and the cumulated power injected in the grid via stator (directly) and via the rotor (via the rotor side and grid side converter) are shown in Fig $6 \mathrm{c}$ and as expected the cumulated grid current shows a $\pm 10 \mathrm{~kW}$ flat top (except the peaks following the sharp power reversal which is caused by some additional overshoots of the current controllers in the rotor side converter. 

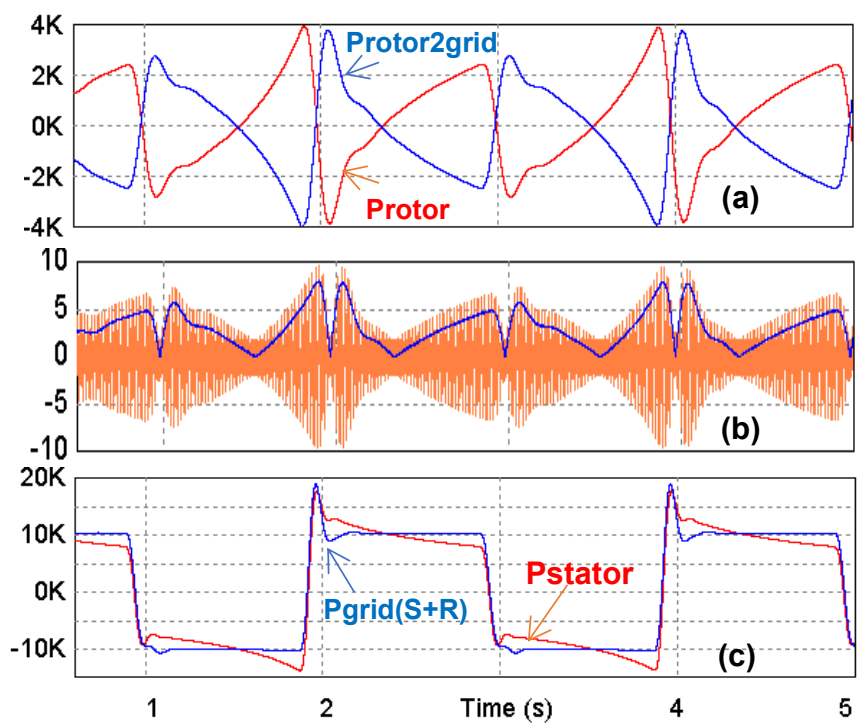

Fig. 6. Simulation results showing the interrelation of rotor side and grid side converters: a) their powers; b) phase grid current and the magnitude of grid current vector; c) stator DFIM power and the summation of stator power and grid converter power proving $10 \mathrm{~kW}$ constant power operation.

It is important to assess the losses caused in both conversion stages of the rotor side converter. To achieve this, the semiconductor losses are estimated using the "thermal model" of PSIM. The relevant on state and switching energy losses of the BSM10GD120DN2 (1200V/15A) IGBT power module form Infineon [7] are used. Fig. 7a shows the evaluation of the IGBT conduction losses of both converter stages. The average IGBT conduction losses in the rotor stage is $16.3 \mathrm{~W}$ whilst in the grid side converter is smaller $(5.4 \mathrm{~W})$. It can be seen that the IGBT conduction losses in the rotor side converter have a significant peak of $48.4 \mathrm{~W}$ near the minimum speed whilst discharging (power is injected in the rotor therefore the rotor converter operates in inverter mode) whilst the IGBT conduction losses of the grid side converter peak at $32.3 \mathrm{~W}$ when rotor power is the largest and is extracted from rotor and injected on the grid (inverter mode).

The conduction losses in the freewheeling diodes follows a similar trend, as shown in Fig. $7 \mathrm{~b}$ however, FRDs are conducting predominantly when the corresponding converter stage performs rectification (power flow from AC side to DClink). FRD conduction loss in rotor side converter peaks at $30.7 \mathrm{~W}$ whilst for the grid side converter is slightly smaller (24.2W). The average FRD losses over a charge/discharge cycle is $10.9 \mathrm{~W}$ for the rotor side converter and $5.2 \mathrm{~W}$ for the grid side converter. The variation of the switching losses during the constant power cycling is shown in Fig, 7c. The rotor side converter switching losses vary with magnitude of the current (torque) peaking at $37 \mathrm{~W}(24.2 \mathrm{~W}$ average) whilst the switching loss in the grid side inverter vary with the rotor power peaking at $24 \mathrm{~W}$ (11.6W average).

The overall losses in the two converter stages as well as the cumulated power loss is shown in Fig. 7d. It is quite obvious that the rotor side converter incurs the largest losses $(94.2 \mathrm{~W}$ peak, $51.4 \mathrm{~W}$ average) whilst the grid side converters' losses are less than half ( $60.4 \mathrm{~W}$ peak and $22.2 \mathrm{~W}$ average). The total loss peak at $144.3 \mathrm{~W}$ with an average over the charge-discharge cycle of $73.6 \mathrm{~W}$ which in relation to the $2 \mathrm{~kW}$ average rotor power processed represents (for a full charge/discharge cycle) approx. $3.7 \%$.
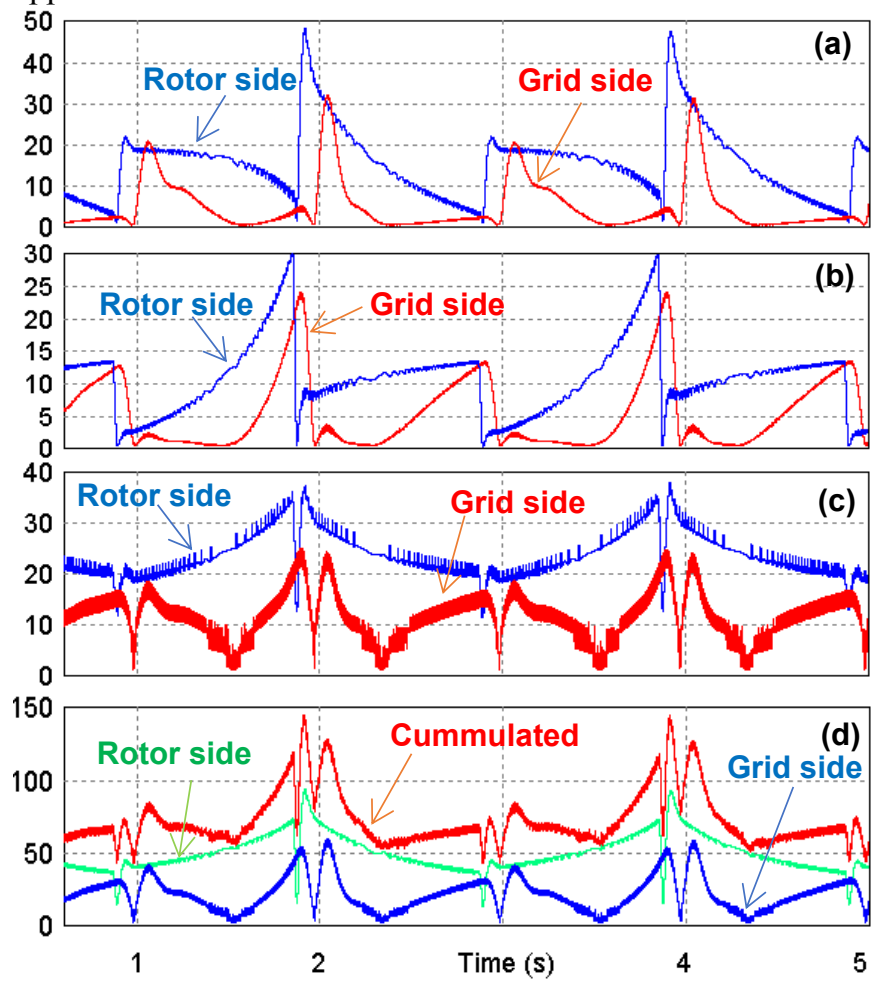

Fig. 7. Variation of power semiconductor losses in the DFIM based F-ESS operating under a $10 \mathrm{~kW}$ constant power charge discharge cycle reported separately for each stage (rotor and grid side): a) IGBT conduction losses; b) FRD conduction losses; c) switching losses; d) cumulated losses.

It should be noted that the charge/discharge electrical efficiency should also account for losses in the stator and rotor winding of DFIM and the associated core losses and mechanical losses which are not evaluated in this paper. However, due to the fact that the bulk of the power is delivered to the grid directly via the stator, it means that although the total converter losses as \% of power processed may be poorer, it is spread over the full power processed by the DFIM, therefore preserving the potential for a high round trip efficiency of the F-ESS.

\subsection{Estimation of losses in the inverter of a SCIM based F-ESS}

It was shown that although the absolute ratings are smaller than the constant power handled $(6 \mathrm{~kW}$ peak power seen by the rotor converter vs $10 \mathrm{~kW}$ constant power handled by the DFIM), the ratio of peak to average stresses handled by the bidirectional converter of a DFIM based F-ESS are worse that in a full scale power converter arrangement. It is thefore necessary to assess the performance and losses of a F-ESS based on a SCIM working in field weakening mode where suposingly the current/voltage/power procecced remains fairly constant which may facilitate a better and more constant utilisation of the power semiconductors which may result in smaller specific losses. 
Fig. 8 shows the simulation results of a $10 \mathrm{~kW}$ constant power charge discharge F-ESS based on a 2-pole SCIM with a base speed of $3000 \mathrm{rpm}$ whihs is also the minimum rotational speed of the F-ESS, whilst the maximum speed is $6,000 \mathrm{rpm}$. To estimate the semiconductor power loss, the on-state voltage drop and switching energy loss of the $1200 \mathrm{~V} / 25 \mathrm{~A}$ Infineon power module (FP25R12KT3) [8] have been used.

Fig. 8a shows the mechanical speed variation vs time, whilst fig. $8 \mathrm{~b}$ shows the stator frequency. The fact that the SCIM drive works in field weakening mode can be deduced from Fig. $8 \mathrm{c}$ where the magnitude of stator flux is shown. The $\mathrm{d} / \mathrm{q}$ reference and actual currents of vector controlled SCIM are shown in Fig. 8d where is clear that the flus producing current changes proportional with the stator frequency to enable weakening of stator flux whilst the torque current remains constant (N.B. the electromagnetic torque actually is product of torque current and flux and modulation of the flux results in similar modulation of the electromagnetic torque which results in constant power operation as illustrated in Fig. 8e). The cumulated conduction and switching power losses in the IGBT (77.9W average and approx. $100 \mathrm{~W}$ peak seen during flywheel charging) and FRDs (56W average and $80 \mathrm{~W}$ flat peak seen during flywheel discharging) as well as the overall loss in the $\mathrm{AC} / \mathrm{DC}$ conversion stage is shown in Fig. 8f.

The total loss of the inverter stage changes very little with the mode of operation and this is mostly due to the fact that there is not a significant difference between the on-state voltage drops of the IGBT and FRD.

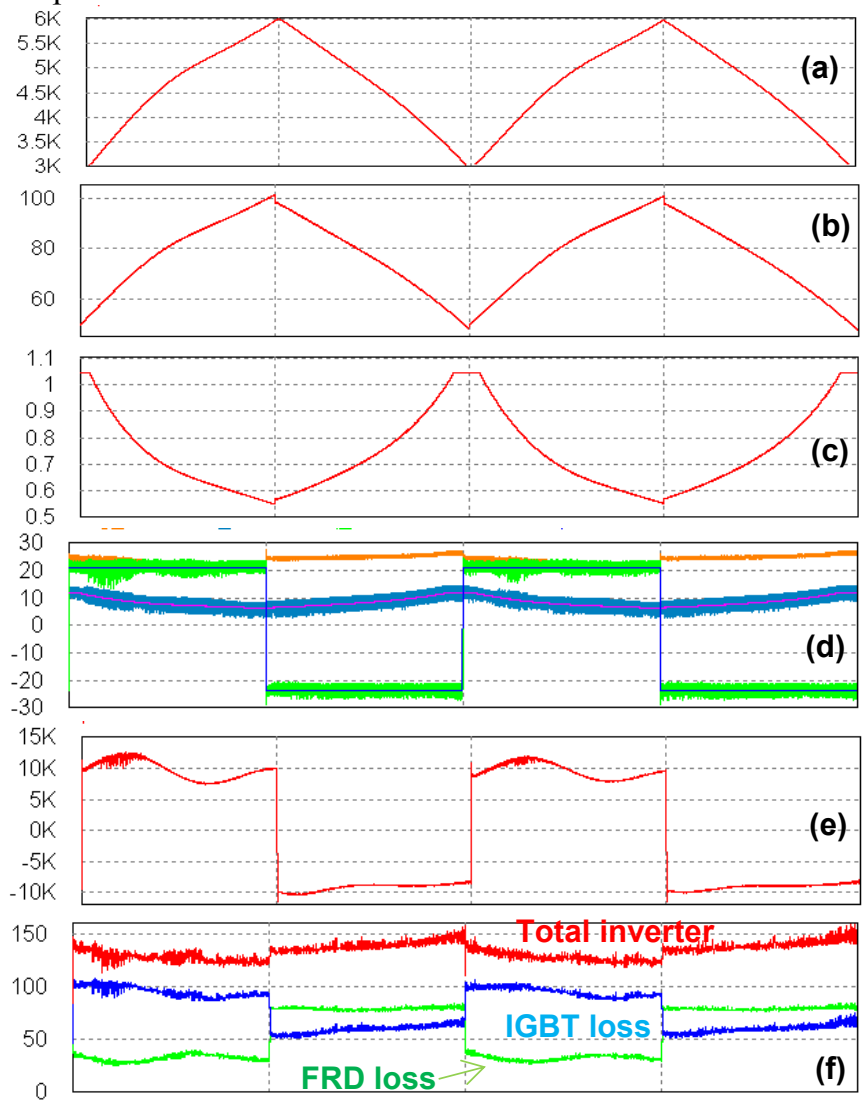

Fig. 8. Simulation results of a SCIM based F-ESS: a) mechanical speed; b) stator frequency; c) magnitude of stator flux; d) d/q reference and actual currents; e) IGBT/FRD and cumulated semiconductor power losses.
The average inverter power loss over a cycle is $133.9 \mathrm{~W}$ with a peak of appox $150 \mathrm{~W}$ which means the heating of the devices is more uniform than in the DFIM converter.. It should be noted that the overall power losses in the bidirectional $\mathrm{AC} / \mathrm{DC} / \mathrm{AC}$ converter that should also include the grid side converter (not modelled) will likely double to approx. $270 \mathrm{~W}$ which is 3.7 times larger than the semiconductor losses of the DFIM converter whilst the peak power processed/installed is only $50 \%$ higher $(10 \mathrm{~kW}$ compared to $6 \mathrm{~kW}$ peak rotor converter power).

\section{Conclusion}

This paper investigated the power converter requirements for a dual-fed induction machine (DFIM) based flywheel energy storage system (F-ESS). The paper started by comparing the particularities of a DFIM used in a wind turbine with the utilisation in a constant powerF-ESS which would require higher rotor currents at lower speed (proportional with slip). On the other hand the energy extraction from flywheel was shown to saturate towards lower speed (higher slip) which means the extraction of energy beyond $70 \%$ of maximum stored energy becomes lossier and less economic doe to the large current ratings of rotor side converter. The paper discussed also the particularities of using different type of AC machines as interfaces to F-ESS. The final part involved the modelling of two F-ESS, one based on DFIM and one on SCIM. It was shown that whilst the ratings of the rotor side converter remains high $(6 \mathrm{~kW}$ compared to a $10 \mathrm{~kW}$ constant power rating of ESS) the average losses are low $(74 \mathrm{~W})$. On the other hand, the SCIM requires a full scale rating power converter which results in larger losses, however if the SCIM is controlled in field weakening mode, the installed converter powercan be close to the actual ESS constant power rating.

\section{References}

[1] Pena, R., Clare, J.C, Asher, G.M, 'Doubly fed induction generator uising back-to-back PWM converters and its application to variablespeed wind-energy generation', IEE Proc Electr Power Appl, Vol 143, No 3, pp 231-241, 1996.

[2] Asher, G, Klumpner, C, "Doubly-fed Induction machines control", lecture notes from Technologies for Wind Generation module, University of Nottingham, Dept of Electrical and Electronic Engineering, 2018.

[3] Akagi. H., Sato. H., 'Control and performance of a doublyfed induction machine intended for a flywheel energy storage system',IEEE Trans on Power Electr,Vol.17,pp.109-116, 2002 [4] Joos G., Abbey C., 'Integration of energy storage with a doubly-fed induction machine for wind power applications', Proc of PESC'04,Vol 3,pp.1964-1968,Aachen, 2004.

[5] Park J. D., 'Simple flywheel energy storage using squirrelcage induction machine for DC bus microgrid systems', Proc of IECON'10, Glendale, AZ, 2010.

[6] Sebastian T., Slemon G., 'Operating limits of inverterdriven permanent magnet motor drives', in Electrical machines and drives Conference, 1993.

[7] datasheet BSM10GD120DN2 power module, Infineon.

[8] datasheet FP25R12KT3, power module, Infineon. 